the several countries visited. Out of his observations Dr. Ranganathan has endeavored to mold a plan for the libraries of India. Like his other works, this volume contains many penetrating statements which illustrate the author's originality and great capacity to comprehend library problems.

Public Library Provision and Documentation Problems contains four papers on public library problems and legislation in India, and 20 papers on various problems of documentation. In the latter group are papers on documentation in several subject fields, abstracting, and arrangement of materials.
In the final paper, on "International Cooperation," Dr. Ranganathan expresses a hope for the establishment of a comprehensive Indian Subject Bibliography.

The third edition of the Colon Classification suggests the continuing interest in the scheme of arrangement that Dr. Ranganathan has been enthusiastically supporting. Students of classification may be induced to read Dr. Ranganathan's remarks on the Colon Classification which appears in Shera and Egan's recent volume, Bibliographic Organization (University of Chicago Press, I95I). -Maurice F. Tauber, Columbia University.

\title{
Father of Plastic Surgery
}

The Life and Times of Gaspare Tagliacozzi, Surgeon of Bologna, 1545-1599, with a Documented Study of the Scientific and Cultural Life of Bologna in the Sixteenth Century. By Martha Teach Gnudi and Jerome Pierce Webster. Preface by Arturo Castiglioni. New York, Herbert Reichner, 1950. xxiv, 538p. 77 plates. \$15.00.

This volume, while it is a biography of the "father of plastic surgery" addressed to the general reader, is also a dynamic picture of life in Renaissance Bologna. It is both an interesting and informative work.

The collaboration of a distinguished plastic surgeon, Dr. Webster, with that of an accomplished archivist of Italian Renaissance materials, Dr. Gnudi has produced a great work of scholarship which dispels many previous errors relating to the great pioneer of plastic surgery. At times, the publication reads like a detective story with the authors piling the evidence higher and higher in order to refute previous erroneous statements. Their documents are given fully in English and are repeated in the original Latin or Italian in an appendix of some 70 pages. The authors provide an English translation of the preface to Tagliacozzi's work De curtorum chirurgia per.insitionem, 1597, reproduce all of its elaborate illustrations, reprint in full Alexander Read's translation of much of Tagliacozzi's book, and provide a comprehensive bibliography and index.

The story of the publication of Tagliacozzi's work, of the difficulties encountered in the legal printing of such a volume, of the formalities and red tape involved and of the almost immediate pirating of the volume by others is a most interesting commentary upon publication activities in the sixteenth century.

The book is a beautiful piece of typography. Appropriately it has been printed and bound in Bologna. The pictorial initial letters incorporating scenes from Bologna or from Tagliacozzi's work were especially designed by Ivan Summers.

This publication should be of additional interest to librarians, for while it represents the culmination of more than 20 years of painstaking research, involving many archives in Italy, it is based in large measure upon publications amassed in a single special collection of a university library. Many librarians take a dim view of special collections for a variety of reasons. One of the principal reasons which give a librarian a sense of frustration, is that so many collections seem to have been gathered solely for the love of the collecting and with no intention of or provision for putting the collection to work.

The more than 12,000 volume Jerome P. Webster Library of Plastic Surgery, lovingly and carefully gathered by its donor, not only provides the literature to support the day-today practice of plastic surgery, but has now been utilized to produce a great work of scholarship in the history of the Renaissance and of surgery.-Thomas P. Fleming, Columbia University. 